\title{
How can middle-income countries improve their skills systems post- COVID-19?
}

\author{
George Herbert
}

23 February 2021

\section{Question}

In middle-income countries in the wake of COVID-19:

- How do vocational training systems need to adapt to build back better and remain resilient and relevant for the future?

- How can vocational training-related interventions increase equity and access for those who most need the training in order to support an inclusive recovery?

\section{Contents}

1. Summary

2. What is the state of vocational training systems in middle-income countries?

3. What has been the direct impact of COVID-19 on vocational training systems?

4. What are the challenges for vocational training systems in the post-COVID era?

5. How should middle-income countries finance vocational training post-COVID?

6. How can middle-income countries improve vocational training quality post-COVID?

7. How can middle-income countries improve access to vocational training post-COVID and .... how can vocational training contribute to reducing inequality?

8. References

The K4D helpdesk service provides brief summaries of current research, evidence, and lessons learned. Helpdesk reports are not rigorous or systematic reviews; they are intended to provide an introduction to the most important evidence related to a research question. They draw on a rapid deskbased review of published literature and consultation with subject specialists. 


\section{Summary}

Vocational training systems in middle-income countries are going to face multiple challenges in the post-COVID era, notably challenges related to: (1) automation; (2) the transition to a green economy, and (3) demographic pressures. Of these, automation - linked to the burgeoning 'fourth industrial revolution' that is set to transform the global economy represents the most serious challenge and is the only one of the three challenges discussed in any depth in this paper. Whilst estimates of the likely scale of automation in the coming years and decades vary widely, it appears likely that waves of automation will lead to a dramatic decline in many kinds of jobs that largely involve routine, repetitive tasks.

These trends pre-date COVID-19, but the disruption caused by the pandemic provides an opportunity prepare for these challenges by implementing vocational training system reforms as part of the Build Back Better agenda.

It is unclear whether low-skilled or intermediate-skilled work will be most affected by automation in practice. Either way there will be huge pressures on vocational training systems. The challenge will be particularly severe if the main impact of automation proves to be a hollowing out of intermediate-skill job opportunities, since these are precisely the kinds of tradebased roles that vocational training programmes have traditionally prepared workers for. Such a hollowing out would also have a negative impact on low-skilled workers, pushing intermediateskilled workers into unskilled roles and creating a downwards pressure on wages.

Middle-income countries, as a group, are likely at particular risk of mass automation. This reflects: (1) high wages relative to low-income countries; (2) the prevalence in many of these countries of routine, factory-based jobs that are highly susceptible to automation, and (3) the failure of education and skills systems in these countries to develop the kinds of higher-level cognitive and socio-emotional skills required by jobs that are hard to automate.

COVID-19 has created serious labour market pressures in the short-term and created major challenges for vocational training systems. Many countries have expanded distance learning opportunities. This can be challenging for certain kinds of vocational training courses, but the pandemic also appears to be stimulating innovation that may expand the possibilities for digital delivery of vocational training going forward. Middle-income countries faced particular issues with online learning due to internet connectivity issues, limited teacher training, patchy device access, and low digital skills amongst many students.

In order to avoid the emergence of a digital divide in access to vocational training opportunities, middle-income countries need to continue to invest in digital infrastructure, and to prioritise developing the digital skills of students.

COVID-19 will likely accelerate the pace of labour market disruption. Social distancing has boosted the transition towards a digital economy and provided another reason for companies to automate jobs. Many companies who have laid off staff in automatable jobs during the pandemic will likely deploy technology during the recovery, so that they do not need to hire as many individuals in automatable jobs as they did prior to the pandemic. Strong systems for monitoring labour market developments and skill requirements will be increasingly important for the design of appropriate vocational training offerings. 
Post-COVID middle-income countries will need to invest more heavily in understanding labour market trends; by making better use of already existing data they should be able to make decisions based on granular, real-time information on labour market developments.

Vocational training systems in many middle-income countries appear ill-prepared to respond to these challenges. Vocational training in middle-income countries varies in quality, but is frequently marked by under-funding and poor-quality infrastructure and teaching. Secondary and tertiary vocational training institutions are often highly focused on learning techniques with limited efforts to build the higher cognitive and socio-emotional skills of employees, with a high proportion of graduates of such programmes going on to work in jobs that are at high risk of automation.

Middle-income countries should adjust vocational training course offerings and curricula where required to ensure students gain enabling skills that will allow them to remain adaptive in a changing workforce; this would include teaching digital skills, developing problem solving skills, and inculcating a learning and entrepreneurial mindset.

Many international institutions see COVID-19 as providing an opportunity for middleincome countries to push forward with vocational training reforms. Notably, this would extend efforts to improve the responsiveness of vocational training institutions by exposing them to market forces, improving engagement with employers and shifting towards modular, bite-sized learning options such as 'micro-credentials'. However, such changes are opposed by other observers who fear that it would involve doubling down on a 'failed' 'new public management' approach, narrowing vocational training offerings and embedding a short-term approach that would hamper the creation and maintenance of strong vocational training institutions.

In reality vocational training systems in middle-income countries will likely need to offer a combination of longer vocational training courses - as an alternative to academic tertiary education - and an expanded range of short course options - to allow workers to update their skills throughout their careers.

The post-COVID era will potentially exacerbate some labour market equity and vocational training access issues. Young people have been particularly affected by COVID job losses, and young and older workers appear likely to be particularly affected by automation. Women face particular challenges accessing vocational training opportunities - often linked to social attitudes, caring responsibilities and personal security issues - female workers may require specific kinds of support in order to adjust to the demands of the digital economy. A shift to digital delivery of vocational training may create access challenges for the poor and other vulnerable groups without reliable access to digital devices and the internet.

Post-COVID Middle-income countries need to carefully consider how to smooth transitions into work for young people, especially those who have had their education disrupted or who have had a gap before entering the labour market due to the pandemic. The approach taken needs to be based on a long-term vision so as to avoid pushing young people into jobs that have poor longterm prospects due to automation.

Middle-income countries should ensure vocational training offerings are accessible to women by - where appropriate - offering support to participants with caring responsibilities (e.g., childcare 
grants) and making adjustments to ensure that participants can feel safe attending trainings (e.g. by providing trainings at distributed sites close to participants homes).

Reforms to vocational training systems will be crucial to ensuring middle-income countries respond appropriately to accelerating labour market changes. However, they should only form a limited part of that response and need to be integrated with a wide range of other policy measures.

Vocational training reform will need to occur in the context to major reforms to basic education in order to ensure that all workers are equipped with the cross-cutting cognitive and socioemotional skills they will require to perform hard-to-automate tasks and to be able to learn and adapt rapidly in a changing economy. Middle-income countries will also likely need to progressively expand social protection schemes in order to provide a safety net for workers that struggle to adapt to changing labour market requirements.

\section{What is the state of vocational training systems in middle-income countries?}

It is widely agreed that improving workforce skills are vital to the development of middleincome countries. A significant literature has developed focused on the "middle-income trap", in which countries that have grown at a rapid rate to middle-income country status, often partly relying on natural resource wealth to do so, stagnate and fail to transition to high-income status. This is widely believed to reflect a failure of economic structural adjustment and low labour productivity growth. Education and skills development are widely considered to be key to avoiding the "middle-income trap", allowing countries to shift their labour-force towards higher skilled, higher productivity employment (Eichengreen et al., 2013).

The evidence on the effectiveness of vocational training programmes in middle-income countries is somewhat mixed. Tripney et al. (2013) reviewed 20 vocational training interventions, all but one of which were in middle-income countries, a found that the interventions had a significant positive effect on the labour market outcomes of participants. However, the effect of these interventions on employment and wages was very small, meaning that it is an open question whether they demonstrated reasonable value-for-money. Moreover, the authors caution that study quality was a significant moderator, with higher effect sizes found on lower quality studies, implying that even the very small average effects observed may represent an over-estimate. Similarly, Chinen et al. (2017) conducted a meta-analysis of 16 randomisedcontrol-trial $(\mathrm{RCT})$ studies assessing the effectiveness of vocational training interventions on adult women's employment prospects in low- and middle-income countries. The authors found a significant but rather small positive effect (participants were $11 \%$ more likely than controls to secure work) alongside non-significant indications that the positive effects of trainings on employment fell when looking at horizons beyond six months post-training.

Often vocational training in middle-income countries fails to prepare citizens for the modern labour market. South Africa's vocational training system has been described as functioning "far from optimally" pre-pandemic (Parker, Morris, Hofmeyr, 2020). Isaacs (2020) presents case studies of the skills systems in three African countries and Bangladesh, identifying vocational training system weaknesses including: 
- Inadequate expertise amongst vocational training instructors;

- Inadequate funding;

- Poor pedagogical resources, and

- Curricula that are not adapted to provide the skills are demanded by employers.

Allais \& Marock (2020) identify that South Africa's vocational training colleges:

- Reach a relatively small number of students;

- Are seriously under-funded;

- Suffer from "serious weaknesses" lecturer capacity;

- Are undermined by excessive "churn" in the qualifications system, and

- Are hampered by "dislocation and lack of integration" with private skills providers.

Beyond formal vocational training institutions, the situation is often even worse. Allais \& Marock (2020) note that South Africa's apprenticeship system is "tiny and full of serious challenges." Isaacs (2020) discusses in more detail weaknesses in the traditional apprenticeship practices which are common in the informal sector across Africa and much of Asia, noting a lack of rigour and consistent standards that can hamper skill transfer. Palmer (2017) also expresses concerns at the tendency of such informal apprenticeships to perpetuate outdated practices (Palmer, 2017) and suggests that middle-income countries should invest in "recognition and certification processes and skill assessment modalities so that skills acquired informally can be validated and more easily recognised."

Unsurprisingly, vocational training in upper middle-income countries appears generally superior to that in lower-middle income countries. For example, Sa-Nguanmanasak, et al. (2019) compared the skills of 'work-integrated learning' students from (upper-middle income) Malaysia and (lower-middle income) Thailand, finding that the former generally had much higher skills.

However, heterogeneity in the quality of middle-income country vocational training also reflects more complex political economy factors. Sancak (2020) argues that increased funding for and reforms to Turkey's vocational training system reflected Turkish party politics, and particularly the ruling AKP party's need to reward its core support base amongst "small and medium enterprises and labour market outsiders". Similarly, Doner and Schneider (2020) argues that vocational training systems in today's advanced economies developed thanks to the demands of broad coalitions of interest that are lacking in today's middle-income countries due to "fragmentation of social groups." As a result, those middle-income countries that have successfully expanded their vocational training systems - notably Chile (now an advanced economy), Turkey and Malaysia - have done so because of a "top-down dynamic led by strong parties and stable governments." 


\section{What has been the direct impact of COVID-19 on labour markets and skill systems?}

The pressures of the pandemic are likely to have further stretched middle-income country vocational training systems that were often already underperforming. This perspective is exemplified by Allais and Marock (2020) who state that existing weaknesses in South Africa's "fragile" skills system have been "reinforced and made more visible" by COVID-19.

The most obvious pressure posed by COVID-19 for vocational training systems has been the imperative of social distancing, which has led to the suspension of many courses and has forced most others to shift to distance learning. As noted in a recent World Bank paper, the "focus on practical skills and work-readiness" inherent in vocational training "makes remote learning particularly challenging" (Hoftijzer et al., 2020). Allais and Marock (2020) are even more emphatic, stating that "while technology can obviously assist learning in many ways...a reliance on online and distance education is completely unrealistic" for vocational training colleges. This assessment reflects the state of the South African vocational training system. In South Africa, few vocational training colleges have "the necessary facilities for online learning or the prior educational background that makes this viable", teachers lacked the skills to deliver trainings online and students lacked "the necessary facilities", suffered from poor connectivity issues (especially those from rural areas), often lacked access to "a calm and quiet space to work" and lacked the digital skills to take advantage of online training effectively. The cost of data also appears have been an issue (Avis et al., 2020 - p.10). The South African example is arguably representative of the challenges existing for remote provision of vocational training in lowermiddle income countries. A high proportion of lower-middle income countries still have issues related to internet access and quality (Majumdar \& Araiztegui, 2020, p.7) and this is likely a particular issue for vocational training students, who tend to come from lower socio-economic backgrounds.

\section{Nonetheless, successful examples of remote vocational training delivery before and} during the pandemic demonstrates that some of the supposed barriers to remote delivery of vocational training may be overstated. Globally Massive Open Online Courses (MOOCs) have allowed huge numbers of people to develop coding skills over the past decade, with more than 1.9 million students from all over the world having enrolled on the University of Michigan's 'Python for Everyone' coding course alone to date (onlinecoursereport.com), whilst Hofheinz (2018, p.75) notes the booming sector of "vocational training for professionals", utilising digital technology, as exemplified by the success of the Udacity website. Remote learning had already been incorporated into vocational training systems in many middle-income and developing countries prior to the pandemic, including:

- In India through the Swayam Prabha Direct-to-Home TV channels;

- In Mexico through the government's 'distance learning programme for workers', which offers short (maximum 10 hour) courses to the unemployed and adults in a situation of "employment vulnerability (Lobo, 2016), and

- In Thailand and Indonesia through the Thai MOOC platform and Rumah Belajar platforms respectively, with the former allowing learners to gain short-course certificates that are recognised by Thai Universities (Karr et al., 2020, p.18). 
Despite the substantial challenge COVID-19 has posed for vocational training systems, some are optimistic that it may "ultimately result in stronger and more resilient VET systems" (OECD, 2020, p.2). This partly reflects the expectation that the COVID-19 pandemic will spur technological and pedagogical innovations that support remote TVET delivery (Hoftijzer et al., 2020). Many middle-income countries have already expanded digital delivery of vocational training during the pandemic. For example, the Kazakh Government was reported to be developing over 2,000 TVET lessons in 2020, Mexico's Capacítate Para El Empleo online portal switched to offering free access to its hundreds of courses and several technical diploma degrees (Hoftijzer et al., 2020) and Morocco's Government created a new e-learning platform for vocational training (Draissi \& Zhanyong, 2020). Virtual reality, amongst other cutting-edge technologies, has particular potential to support remote vocational training (Hoftijzer et al., 2020 - p.11) and additional funding flows to vocational training centres during the pandemic may provide an opportunity for long-term investment in such technologies (OECD, 2020, p.7). For example, Bilsand et al. (2020) report adoption of both "e-internships" and "simulated internships" to support learning by hospitality students during the pandemic.

\section{Looking beyond the imperative of remote learning during the pandemic, there are} potentially large gains from such changes. Even in normal times remote training provision has huge potential benefits in terms of cost, scalability and access for those based in remote areas. Opportunities for digitalisation of training could also extend to foundational training of vocational trainers themselves (OECD, 2020, p.7), something which is an important consideration given skills weaknesses in trainers themselves in many middle-income countries. Bilsland et al. (2020) draw parallels between the value of e-internships in the service sector and the use of flight simulators in pilot training; virtual learning environments have advantages over real-world internships, because they can be used to deliberately expose students to a wide variety of rare events that it might take years of work experience to encounter naturally, allowing interns to "learn how to manage many more circumstances" and how to respond with a "serviceminded approach."

Not all observers are convinced that such changes will be good for vocational training systems. Avis et al. (2020, p.11) fear that a new focus on the digitalisation of vocational training post-COVID could lead to "hollowed out" vocational training systems. Certainly, an expansion in remote delivery of vocational training will make it increasingly important for middle-income country governments to take steps to prevent the emergence of a "digital divide in vocational education" in which vulnerable and economically disadvantaged individuals and communities are left behind due to their lack of access to the required technology or digital skills to access training (Hoftijzer et al., 2020, p.11; Pearson, 2020, p.58).

\section{What are the challenges for vocational training systems in the post-COVID-19 era?}

In the post-COVID world middle-income country skills systems will need to ensure their skills offering are appropriate given three critical challenges: (1) the development of the digital economy and the 'fourth industrial revolution', and especially the challenge posed by mass automation; (2) the need to transition towards the 'Green Economy'; and (3) demographic changes. This section focuses primarily on the adjustments required given the expected impact of the fourth industrial, since this appears to be the issue which will likely have by far the largest 
impact on labour markets and which will almost certainly affect all middle-income countries. The other two issues are discussed briefly.

\section{The fourth industrial revolution}

The fourth industrial revolution is a concept closely linked to the development of the global "digital economy", but goes beyond this, referring to how technological advances and their economic applications are "blurring the lines between the physical, digital, and biological spheres" (Schwab, 2017, p.1). These changes are happening at a pace that "has no historical precedent", with the changes of previous industrial revolutions appearing slow by comparison., and the disruption is affecting "every industry in every country" (Schwab, 2017, p.7). As it progresses it is expected to transform "entire systems of production, management, and governance" (Schwab, 2017, p.7) with a huge impact on the nature of work and therefore on the demands on skills systems throughout the world.

\section{What impact will the fourth industrial revolution have on labour markets globally?}

There is a broad consensus amongst economists that the pace of labour market change and disruption is accelerating as the "fourth industrial revolution" takes hold (The Asia Foundation, 2020). The most obvious way in which labour markets will be affected is through the automation enabled by advances in artificial intelligence and robotics. We currently lack the required understanding of the limits and pace of technological progress in these fields to make precise estimates of the scale of labour market disruption likely to occur through automation in the coming years. However, a fairly extensive literature has developed, which - whilst providing variable estimates and largely focused on advanced economies - is unanimous in indicating huge disruption. One of the earliest estimates, by Frey and Osborne (2013), suggested that 47\% of US jobs were at high risk of being automated. Later estimates have generally been lower, with Arntz et al. (2016) providing an estimate of just 9\% and Nedelkoska and Quintini (2018) estimating that $14 \%$ of jobs in OECD countries are "highly automatable", with another $32 \%$ of jobs have a $50-70 \%$ risk of automation. All these studies agree that even amongst those jobs that cannot be fully automated, technological change will create huge changes in the balance of tasks conducted by workers and the skills they will require.

The impact of automation on employment is not vague future-gazing; its impact is already visible. Nedelkoska \& Quintini $(2018$, p.7) note that the share of jobs rich in tasks that are hard to automate has been growing in recent years, indicating that the labour market is already adjusting to shed jobs that are rich in automatable tasks, and create jobs that complement new technology production inputs. Even more strikingly, the authors use data on the last occupation of unemployed individuals in OECD countries to reveal that there is already a 44-percentage point difference in the unemployment rate between the least and most automatable occupations, whilst those employed in the least automatable occupations work eight hours more per average than those in the most automatable jobs. This indicates that automation represents one of the major drivers of unemployment and under-employment today.

Jobs dominated by repetitive, routine tasks being much easier to automate than roles requiring imagination, novel problem solving and emotional intelligence. As noted by the $\operatorname{OECD}(2020, p .7)$, it is "occupations involving routine tasks" - particularly manual tasks but also clerical and administrative ones - that are being "transformed, restructured or disappearing 
entirely due to increasing levels of automation." In contrast, "bottlenecks to automation" (Nedelkoska \& Quintini, 2018) mean that, based on our current understanding of the challenges involved in artificial intelligence research, jobs rich in certain kinds of task remain relatively secure. These bottlenecks include "social intelligence, such as the ability to effectively negotiate complex social relationships..., cognitive intelligence, such as creativity and complex reasoning; and perception and manipulation, such as the ability to carry out physical tasks in an unstructured work environment" (Nedelkoska \& Quintini, 2018).

There is no consensus regarding whether low-skill or intermediate-skill jobs are most at risk of automation in practice. Indicative of two competing visions of the future of the labour market are researchers who suggest the fourth industrial revolution will cause labour market polarisation by "hollowing out" intermediate-skill-level jobs whilst increasing demand for high- and low-skilled work (Shiohira \& Keevy, 2019; Autor, 2010), and those who claim there is a "monotonic decrease in the risk of automation as a function of educational attainment and skills levels" (Nedelkoska \& Quintini, 2018, p.8).

Nedelkoska \& Quintini (2018) present evidence indicating that low-skilled work is the most susceptible to automation. The jobs they identify as most at risk of automation are generally those that "do not require specific skills or training", giving examples such as "food preparation assistants, assemblers, labourers, refuse workers, cleaners and helpers." Indeed, personal care work is the only kind of work generally classified as low skilled that they classify as having a low risk of automation. However, their analysis does identify significant risks to intermediate-skill jobs as well. Their second most vulnerable category of employment are jobs that require "some training", but where a large proportion of job content involves interaction with machines; this includes "machine operators, drivers and mobile plant operators, workers in the processing industry, skilled agricultural workers, [and] metal and machine workers."

In contrast, Shiohira \& Keevy suggest that intermediate-skill jobs are the most vulnerable to automation in practice. The routine, repetitive nature of many intermediate-skill jobs makes it technically feasible to automate them, whilst higher wages mean that automation can generate "considerable cost savings for employers" relative to automating low-skilled jobs. This would represent an acceleration of existing trends towards labour market polarization characterised by growth in both low-skill and high-skill employment combined with a decline in many categories of intermediate-skill work (World Bank, 2016; 2019; Autor, 2010).

\section{What is the likely impact of the fourth industrial revolution on middle-income countries specifically?}

It seems almost certain that middle-income countries will be seriously affected by the fourth industrial revolution, including through automation. Whilst relatively little research has been conducted on the labour market implications of automation in middle-income countries specifically the digital economy is growing rapidly in middle-income countries (Herbert \& Loudon, 2020). Theoretical research by the World Bank concludes that "middle income countries are the most at risk of being negatively affected by automation" (Bentaouet Kattan et al., 2018). The risks of automation in middle-income countries are reduced, relative to advanced economies, by their lower labour costs and lower capital availability. However, the risks are heightened by low levels of educational achievement (including poor literacy and numeracy skills as measured by the international PISA framework) (Bentaouet Kattan et al., 2018) and the prevelance of repetitive 
factory-based work which is particularly susceptible to automation (Nedelkoska \& Quintini, 2018), such as the large automobile manufacturing sectors in India, South Africa and Mexico (Banga \& te Velde, 2018). A particular issue for middle-income countries concerns the likely impact of automation on the informal sector - given the high proportion of their labour markets employed informally - but the literature on this issue appears very limited.

Technological changes, including automation, in middle-income countries already appear to be causing "job polarisation", with a fall in intermediate-skilled work opportunities forcing more into low-skilled work. The research that has been conducted for middle-income and developing countries generally suggests that intermediate-skilled occupations are in decline, forcing many into low-skilled work and therefore exerting downwards pressure on unskilled labour (Park \& Inocencio, 2020). Maloney and Molina (2016) show that intermediate-skilled occupations (intensive in routine cognitive and manual tasks) have decreased across developing countries. Fleisher et al. (2018) find evidence for job polarization in China from 1995 to 2013. Dao et al. (2017) argue that developing countries which have undergone greater routinization of tasks and are more closely linked to global value chains have experienced greater declines in the income-share of intermediate-skilled workers. Some of the estimates on future automation risks for middle-income countries are worryingly high. For example, the World Economic Forum (2017) estimated that $52 \%$ of formal sector jobs in Kenya were susceptible to automation.

\section{What are the implications of accelerating automation for vocational training systems?}

Vocational training systems will need adapt to provide young workers with skills that will make them resilient to automation and to re-skill workers affected by automation. To achieve their objectives vocational training systems will need to provide workers with the skills required to allow them to prosper in the context of automation and to avoid creating an oversupply of skills that are unlikely to retain their value. Adult learning systems will be "crucial" for retraining and up-skilling workers whose jobs are affected by technology, and therefore for maintaining economic resilience and achieving rising living standards in the 21 st century. Hofheinz (2018, p.75) argues that the old 'work-life' balance needs to be reconceptualised as a "work-life-education balance", reflecting the importance of continuous re-skilling and skill upgrading in the 21st century economy. The Asia Foundation (2020, p.16) agrees, noting that "lifelong learning" will become an increasingly important principle for ensuring labour market effectiveness in middle-income countries. They suggest that governments need to find ways to "incentivize businesses to upskill their workers" continuously over the course of their careers. In this context strong, forward-looking skills systems are likely to be more important than ever (Park \& Inocencio, 2020).

The pace of labour market changes expected may require governments to adopt more radical approaches to workforce re-training. Nedelkoska and Quintini (2018) show that, over time, workers in high-automatability jobs in OECD countries have been re-skilling and moving towards jobs that are less automatable. However, that re-qualification typically involves only a slow drift away from highly automatable occupations with a difference in automatability between workers' first and second occupational qualification of only $1 / 7$ of a standard deviation. This likely reflects workers lacking confidence (or the pre-requisite skills) to re-train for an occupation fundamentally different from the one they are currently working in. This slow drift away from automatable jobs may be too slow to cope if the rate of technology-driven automation speeds up significantly in the coming years. Governments may need to consider policies that support 
workers to adopt more radical re-training programmes - for example, through re-training subsidies for more expensive qualifications or through efforts to build the foundational skills of workers in order to enable them to begin a new qualification that will allow them to begin work in an occupation quite different to their prior experience.

The debate on whether automation will result in a hollowing out of intermediate-skilled jobs or will hit low-skilled jobs worst has significant implications for vocational training systems. If Nedelkoska and Quintini are correct, then middle-income countries that invest in vocational training systems that raise individuals from low to intermediate skill should improve their resilience to the effects of automation. However, if Shiohira and Keevy are correct, automation will have the worst effect on precisely the kind of intermediate, trade-specific skills gained commonly associated with vocational training (Shiohira \& Keevy, 2019, p.3). Focusing on traditional vocational training would therefore involve wasting significant resources flooding labour markets with workers with valueless skills. One potential implication would be that governments should prioritise improving basic education rather than vocational training, since the former is associated with the development of the broader cognitive skills required by jobs that are hard to automate.

In the labour market of the fourth industrial revolution observers expect that technical skills will often need to be paired with higher cognitive skills; this could lead to vocational training systems focusing on providing top-up technical training for individuals with strong academic qualifications rather than providing an alternative for those who struggle in academic education. Various observers suggest that the fourth industrial revolution will increase labour market demand for a new kind of worker which blurs the boundaries between 'blue-collar' and 'professional' careers. So-called "new collar" workers offer both technical skills and higher academic qualifications, something in evidence in IBM's partnership with vocational training institutions to refine their curricula (McKinsey, 2018). This could serve to breakdown the current association of vocational training as a second-rate alternative to university education, whilst simultaneously squeezing individuals with low academic attainment who could previously have built good careers by achieving technical qualifications.

The kinds of courses offered by vocational training systems will need to shift significantly to meet changing labour force requirements. Commentators have made various suggestions regarding how the curricula offered by vocational training systems needs to be updated in order to take account of the needs of the new economy. For example:

- Shiohira and Keevy (2019, p.11) suggest that there needs to be a greater focus on entrepreneurship and innovation in vocational training institutions;

- The World Economic Forum (2017) has advocated that vocational training systems worldwide should put a much greater focus on digital skills, and

- The OECD has argued that countries should use the opportunity provided by the pandemic to shift their vocational training systems towards a strong focus on occupations "demanding higher levels of autonomy, planning, team-work, communication and customer service skills that are more able to resist automation" (OECD, 2020). Specifically, the OECD suggests a greater focus on vocational training for "resilient and future orientated" sectors, including "renewable energy, IT and biotechnology" which it suggests are "more resilient and future orientated." 
Are the vocational training systems of middle-income countries prepared for the challenges posed by the fourth industrial revolution?

Skills systems in many middle-income countries generally appear ill adapted to prepare workers for the challenge of the future labour market. Pellini et al. (2019) suggest that "education and research systems in most middle-income countries are not fit for purpose" because they are not preparing citizens for the challenges of the fourth industrial revolution. This aligns with calls by many observers for middle-income countries to increase their investment in the digital skills of their workforce (Chetty et al., 2017), as well as for them to adapt vocational training offerings to incorporate 21 st century skills, including through trainings related to robotics and artificial intelligence (Shiohira \& Keevy, 2019, p.8).

Efforts to adapt the courses offered by vocational training institutions and to modernise their curricula have been pursued by various middle-income countries in recent years. For example, a 2016 Indonesian Government decree sought to promote acquisition of skills relevant to "Fourth Industrial Revolution competencies" such as "augmented reality, virtual reality, 3D printing, tourism promotion, game development, smart schools, the internet of things, ecommerce, and entrepreneurship" (The Asia Foundation, 2020, p.57).

\section{What are the implications of the COVID-19 for labour markets and vocational training systems, particularly in middle-income countries?}

COVID-19 has highlighted the importance of economic resilience and the role of vocational training systems in promoting such resilience. Since the COVID-19 pandemic began an increasing amount of attention is being paid to issues of economic resilience, including in middle income countries (Herbert, 2020). Vocational training systems can enable countries to respond more effectively to crises. Evidence from past health crises indicates that vocational training systems can play an important role in crisis response; for example, in low-income Sierra Leone the National Ebola Training Academy provided short clinical training modules for frontline Ebola health care workers and was found to have contributed to controlling the outbreak (Hoftijzeret al., 2020 - p.7). This has been demonstrated again during the COVID-19 pandemic when governments have sought to rapidly re-train workers to take on new roles, such as in trackand-trace teams. Vocational training systems have proven better adapted than academic institutions to deliver the "short-term, targeted and modular training" that meets such requirements (Hoftijzer et al., 2020). Vocational training systems can also promote economic resilience by enabling countries to adjust more rapidly to structural shocks, such as technological disruption to terms-of-trade shocks.

The COVID-19 pandemic has "emphasised the crucial importance of many practical service sector jobs that are often not highly paid, but are critical enablers of other economic activity. Notably a spotlight has been shone on the importance to society of health care professionals, child and elder care workers, grocery store employees, logistics workers, and ICT support staff" (Hoftijzer, et al., 2020). The pandemic may have a long-term effect on perceptions of the value and skilfulness of different forms of work (e.g. in relation to caring roles, which are frequently treated as low skill).

COVID-19 is accelerating the transition towards a 'digital economy' and automation. Although COVID-19 is having a hugely negative economic impact overall, not all industries, 
companies and workers have been affected in the same way. As noted by Park and Inocencia (2020), in the midst of the pandemic the share prices of many global tech giants continued to climb, whilst the revenues of some businesses using innovative technology - notably in the online retail and food delivery sector, companies producing personal protective equipment using $3 \mathrm{D}$ printing and video conferencing companies - saw strong revenue growth. The pace of automation appears likely to have increased as a result of COVID-19. This partly reflects the fact that automation, on top of efficiency benefits, makes it easier for companies to operate whilst maintaining social distancing (Park \& Inocencio, 2020). In addition, there is evidence from advanced economies that recessions accelerate trends towards automation. The US recessions in 1991, 2001 and 2009 - unlike those in previous eras - were followed by "jobless recovery", where economic growth significantly outstripped job creation. Siu and Jaimovitch (2015) attribute this to the fact that workers in routine jobs laid off during the recession were frequently replaced through automation in the recovery. This means that a high proportion of the many routine jobs lost during COVID-19 may not return during the post-pandemic economic recovery.

These changes mean that many workers will likely need to re-skill in order to re-enter the labour force post-pandemic. Workers who lost automatable jobs may need to re-train to secure work during the recovery. The digitalisation of the economy spurred by the pandemic will likely accelerate the creation of jobs demanding high levels of skills related to digital technology (Hoftijzer et al., 2020). The "turbulent, fuzzy" and unpredictable "new normal" post-COVID will likely also reward workers with competencies such as "imagination, curiosity, creativity, and resilience" (Buheji \& Buheji, 2020) and with "socio-emotional skills that promote adaptability" (Hoftijzer et al., 2020). This situation creates an imperative that "bottlenecks preventing demandresponsive training provision are addressed and that training programs and skill development systems are appropriately reimagined, reset and reworked" and provides an unparalleled opportunity to accelerate vocational training reforms (Hoftijzer et al., 2020). In the aftermath of COVID-19 middle-income country governments will need to invest in the research and analysis required to understand how the courses they provide should respond to the changing nature of the economy (Hoftijzer et al., 2020, p.9).

In the short-term demand for vocational training will likely be strongly affected by the pandemic. Inflows into work-based training schemes are likely to have dropped during the pandemic; this has been the case in South Africa, where employers report not wanting to take on trainees given "restrictions on the number of workers allowed in different work spaces." In addition, a substantial number of individuals who were participating in vocational courses prior to the pandemic may not return once training re-starts fully (Hoftijzer et al., 2020, p.8). This is likely to be especially the case amongst students from economically disadvantaged backgrounds, who may face particular pressures to begin earning money quickly in order to support families which have depleted savings during the enforced downturn. Conversely, post-pandemic there may be a surge in demand for courses from new students, including from individuals who did not complete regular education as a result of the disruption caused by the pandemic, who have deferred starting courses or who realise that they will need to re-skill in order to find work in the new economy (Hoftijzer et al., $2020-$ p.9).

Changes to international labour mobility wrought by the pandemic may have particular implications for some middle-income and low-income countries. Poudel (2020) argues that the majority of Nepali vocational training programmes will be "irrelevant" post-COVID because they "were designed targeting the skills of the international labour market." However, "millions" of 
Nepali migrant workers have returned home during the pandemic and the author anticipates that the outflow of migrant workers will now be halted "for some years." The author recommends designing programmes "based on indigenous knowledge systems" in order to support the integration of returnee migrant workers into the Nepali economy.

\title{
Demographic issues in middle-income countries and their implications for vocational training systems post-COVID
}

\begin{abstract}
Whilst the huge pressure on healthcare systems created by the pandemic will likely retract as the disease is brought under control, middle-income countries are likely to need to expand their health and care sector labour force permanently. This partly reflects demographic trends and the natural structural consequences of transition towards high-income country status, but it also relates to the way COVID-19 has revealed the importance of retaining slack in the health system in order to promote resilience when unexpected public health shocks occur (Woo, 2020; Herbert, 2020). It seems probable that the pandemic will mark a long-term increase in demand for skills related to public health (Hoftijzer, Levin, Santos \& Weber, 2020).
\end{abstract}

The size of a 'demographic dividend' for many middle-income countries will likely be contingent on their ability to equip their growing workforces with the skills required for productive employment. Many middle-income countries have the potential to take advantage of what is often referred to as a 'demographic dividend' as the relative size of their working age populations rise as they transition from high to declining fertility. This is especially the case for middle-income countries in Africa (Drumond \& Thakoor, 2014), whilst in middle-income Asia much of the demographic dividend has already been realised (Ha \& Lee, 2016). However, "investment in human capital is critical to harnessing the demographic dividend", providing another reason why middle-income countries need to improve the quality of their skills systems. Without such investment there is a risk of large numbers of young people coming onto the labour market without the skills needed to secure productive employment (Isaacs, 2020; Cuaresma et al., 2014).

\section{How will the development of the green economy affect labour markets?}

Adoption of green technology, and the re-deployment of labour from existing fossil fuel intensive industries, will likely require vocational training systems to develop new courses and expand their offerings. As noted by the ILO (2019), "the essential process of transition to the green economy may disrupt labour markets and will require reskilling and upskilling of workers to reduce the risk of rising unemployment, poverty and inequality." Majumdar and Araiztegui (2020) identify the pandemic as providing "an opportunity for reimagining" vocational training, with a particular focus on "greening skills." Vocational training systems will need to cater for the needs of disparate groups to support the transition to a low carbon economy. In particular trainings will likely need to "disaggregate for and target different skill levels and age groups - from young people learning advanced technology skills in frontier industries to experienced manual workers in declining industries" (Genscu et al., 2020, p.8). 


\section{How should middle-income countries finance vocational training post-COVID?}

Financing vocational training is a challenging issue for middle-income countries at the best of times, but the combination of high demand and fiscal constraints in the wake of the pandemic are likely to pose a particular challenge. The huge economic and societal disruption generated by the COVID-19 pandemic has prompted numerous comparisons to major wars. This conception of the COVID-19 response as involving a wartime footing has already been matched by rhetoric advocating a huge scale economic recovery plan analogous to that deployed by many western nations in the aftermath of World War 2 (Pennington \& Stanford, 2020). As in the post-war era, politicians have frequently referenced the importance of expanding vocational training opportunities in order to get society working again after the huge job losses and disruption of the pandemic (Avis et al., 2020). However, the substantial debts accumulated by many governments during the pandemic will create severe fiscal pressures in the coming years for many governments, including middle-income countries (Ejiogu, et al., 2020; Goyal, 2020). Many middle-income countries may face struggle to finance the expansion to their skills systems that will likely be required to enable them to adjust effectively to the labour market shocks of the coming decades.

\section{Relying on market forces to deliver an adequate supply of vocational training is} problematic. Relying on self-financing by workers would create major equity challenges and could create social tensions. Workers may also invest less than the societally optimal amount in their own training reflecting issues securing loans to finance training and information asymmetries between workers and employers. Similarly, employers tend to under-invest in employee training from a societal perspective, due to the risk that they pay for training which allow employees to move to competitors on higher wages (Glick et al., 2015). Employer underinvestment is a particular problem during downturns, when employers tend to reduce workplace training schemes, such as apprenticeships (OECD, 2020, p.2) - this appears a significant problem in the current environment given the potential for a slow recovery from the economic disruption caused by the pandemic. A purely market approach could therefore lead to slower adjustment to economic shocks at a time when there is more need than ever for labour market flexibility.

Apprenticeship schemes can be an effective way of delivering vocational training in situations where there is limited financing available for course-based learning. Employerbased financing schemes, notably apprenticeships, involve on-the-job training with young workers benefiting from the training provided, and effectively paying for it through the fact that they generally receive lower wages than those available in the open market (Jain \& Sasiprabhu, 2020). Such schemes are some of the oldest forms of vocational training and have real benefits, particularly in fiscally constrained environments. However, they can be subject to quality issues and abuse, with the value of the training received depending to a great extent on the attitude taken by the employer.

Middle-income countries could consider increasing their use of ear-marked funds from specific taxes or levies to finance vocational training programmes. Whilst such earmarking does not directly ease fiscal constraints, and is frequently criticised by academic economists, it may serve to reduce political economy barriers to increasing public funding for re-training programmes. Since 2015 the Government of Alberta, in Canada, has used funds from carbon 
charges partly to fund re-training of individuals working in the fossil fuel sector to enable them to secure jobs in the growing renewable sector (Gençsü, et al., 2020). A more common option in middle-income countries are skills levies, such as that utilised in South Africa (Allais \& Marock, 2020 , p.68). These can be deployed innovatively in order to create stronger incentives for firms to train their workers; in Singapore only those employers who do not make the commitment to make a given level of investment in employee training are required to pay the levy (The Asia Foundation, 2020, p. 102). One under-explored option would be using some of the money raised through digital services taxes to finance vocational training programmes designed to build digital skills.

\section{How can middle-income countries improve vocational training quality post-COVID?}

The "building back better" agenda represents a potential opportunity to push forward with much needed reforms to vocational training systems. The World Bank argues that postpandemic vocational training systems need to think "at the systemic level in ways that support a coherent lifelong learning ecosystem" (Hoftijzer et al., 2020, p.9). They are promoting a "building back better" for vocational training systems focused on (1) improving alignment of vocational training with labour market needs, and (2) developing a more flexible menu of options for vocational training courses that can fit around the schedules of students with complex personal and work commitments.

Recent years have seen a push in many countries to inject more market competition into vocational training systems and some believe this should be extended in the post-COVID era in order to provide a level of flexibility and responsiveness to match the accelerating pace of labour market change. China's labour market has been radically transformed since the 1990s, with a huge shift of workers from subsistence agriculture into the manufacturing sector, and major subsequent shifts in the sectoral composition and skills requirements of industrial jobs. A key lesson that has been drawn from this experience is that diversifying the provision of vocational training services using the private sector is critical to reaching scale and to ensuring that providers remain responsive to labour market needs (Gençsü, et al., 2020). Similarly, the World Bank (Glick et al., 2015) has argued that using private sector providers to deliver vocational training "in a managed competitive framework" can "improve efficiency, quality, and coverage."

One way of increasing market competition whilst achieving equity objectives is through voucher schemes. In recent years some advanced economies, including Canada and Scotland, have introduced grant and voucher schemes which allow workers to choose training that matches their needs delivered by private sector suppliers (Gençsü, et al., 2020). The evidence on the effectiveness of voucher programmes is mixed. Evidence from a vocational training subsidy scheme in Columbia suggest that they can have positive outcomes for disadvantaged workers (Attanasio et al., 2015). However, a comparison of multiple US vocational training programmes indicates that voucher-based schemes often have less impact for poor participants than more prescriptive models for re-training workers (Barnow, 2009).

Middle-income countries will need to strike a careful balance between quality assurance of vocational training and ensuring that training offerings are able to evolve quickly enough to keep up with changing labour market requirements. A key issue likely to face 
countries around the world given the pace of technological change concerns the need to balance: (1) ensuring that training remains of the right quality and appropriate; (2) ensuring that the training provided can adapt quickly enough to remain relevant (Gençsü, et al., 2020). Accreditation-based education and training tends, almost inevitably to suffer from inertia (Gençsü, et al., 2020). Post-COVID governments will need to consider whether regulatory streamlining is required in order to strike the right balance (Hoftijzer, Levin, Santos \& Weber, 2020 - p.9).

\section{The World Bank, the OECD and The Asia Foundation have all made the case for vocational training systems adapting to enable employees to achieve "micro-credentials". The World Bank argues that providing opportunities for "shorter and more modular training with stacked micro-credentials" would support progressive re-skilling whilst enabling participants to earn a living (Hoftijzer et al., 2020), whilst the $\operatorname{OECD~}(2020$, p.7) argues that countries should prioritise the development of systems to enable the recognition of online micro-credentials gained during the pandemic (2020, p.7). Similarly, The Asia Foundation $(2020$, p.8) was advocating prior to the pandemic for a focus on "innovative, flexible credentialing models" in ASEAN countries, including "micro-masters".}

Increasing private sector involvement and the shift towards bite-sized trainings is controversial with some who fear that it will hollow-out vocational training offerings. Avis et al. $(2020$, p.2,12-13) fear that the pandemic has "set the stage" for further attempts at neoliberal reform within the vocational training sector, strengthening pressure from organisations like the OECD for a "narrower atomised" vision of vocational training focused on "specific skills, mainly offered online." The authors feel this would increase inequities in a system with "already profoundly unequal outcomes." Allais \& Marock (2020, p.70 \& 75) are similarly concerned that COVID may entrench the "failed market dogma" of "new public management" derived vocational training reforms, including increasing market competition and increasing the autonomy of public providers. The authors argue that such reforms have been attempted around the world for the past 30 years "with very little success." Continuing in the same vein would, they argue, work contrary to the objective of achieving a "more responsive, agile, demand-led TVET" by preventing the development and sustainability of "strong, robust, healthy institutions."

\section{Such critics point to the risk of a shift to a narrower approach to vocational training that} may not prepare individuals well for the future workforce. Both Allais \& Marock (2020) and Avis et al. (2020) are concerned that a shift towards narrower training offerings which allow individuals to gain "micro-credentials" will lead to a hollowing out of more traditional, longer vocational training offerings. Avis et al. (2020) suggest that micro-credentials and calls to focus vocational training systems on "more resilient and future-oriented" occupations "raises the spectre" of a return to "narrow approaches to training" utilised in the UK during the Thatcherite 1980s. Allais \& Marock (2020) argue that "a broad and general education makes people more able to be retrained and more flexible and able to transition" and that vocational training offers "education to people who have not succeeded in general education." They suggest that a shift to very narrow courses designed to fill immediate labour market needs will have hidden opportunity costs.

These critics promote an alternative, "holistic" vision of vocational training post-COVID. Avis et al. (2020) advocate using the crisis as a moment to forge a vision for vocational training that rejects "narrow instrumentalism and [an] exclusionary association with waged employment", 
encompassing the "needs of the unpaid and those excluded from waged employment but who are nevertheless engaged in really useful labour." They advocate a post-COVID shift towards vocational training systems built around "occupational streams and clusters... with strong qualifications that allow for some local flexibility" (Avis et al., 2020, p.75). Similarly, Allais and Marock (2020) argue that the "narrow supply and demand model" of vocational training should be replaced by a "holistic" approach to thinking about education and work that enables "agile stability". They argue that in the post-COVID era national vocational training strategies and skills development programmes should be integrated with governments' industrial strategies so that governments can build economies with desirable work opportunities for their workforce, rather than simply taking the demand for labour as a brute fact.

Interlinked with this debate is another regarding whether vocational training providers should increase their focus on "transversal", "transferable" or "foundational" skills (OECD, 2020, p.7) relative to job-specific technical skills. This possibility is underpinned by an appreciation that individuals relying on a narrow set of skills and expertise are "unlikely to sustain long-term careers in [the] economies of the future" (World Economic Forum, 2017). If, it is argued, vocational training institutions focus on task-specific technical skills they "depreciate and become obsolete" rapidly (Park and Inocencio, 2020), whilst if they can provide transversal skills they will "stand the test of time" (Shiohira \& Keevy, 2019, p.8). In practice this would mean a shift towards "learning to learn", and developing socio-emotional, critical thinking and digital skills (Shiohira \& Keevy, 2019), which some also claim can be "easily taught at a distance" (OECD, 2020). The OECD argues that such trainings skills could help "economies recover more quickly following a crisis, by helping workers more easily transition into other sectors or jobs."

These debates point to a number of competing visions for the future of vocational training systems. All acknowledge the importance of both transverse and technical skills, but they disagree regarding whether the best way to equip workers with those skills is through:

- Relatively long, broad-based vocational training programmes delivered by, normally, state-run or supported vocational training institutions

- A system in which basic education is the primary mechanism for the development of lifelong transversal skills with a multitude of private sector providers supplying workers with bite-sized periods of vocational training across their careers in order to keep them up-to-date with regards to the specific technical skills demanded by the labour market

- Market-driven provision of transverse skills as well as technical skills, with private sector providers directly teaching skills such as critical thinking and socio-emotional ability through short, potentially online, courses

\section{When considering these alternative visions governments will need to consider:}

- Whether basic education alone can provide the required transverse skills for those workers not completing academic higher education

- Whether broad-based vocational training can be used effectively to upgrade the transverse skills of young people who have struggled in basic education and of older individuals who have already entered the workforce without acquiring such skills 
- Whether higher cognitive and emotional skills can be taught effectively directly and through bite-sized trainings, potentially delivered remotely

In reality, both traditional, long vocational training courses and bite-sized courses will likely have an important place in equipping workforces for the challenges of the fourth industrial revolution. Relatively broad-based and lengthy vocational training courses are likely to remain important as an alternative form of career preparation for those individuals for whom academic higher education is not appropriate. However, such programmes are likely to require significant adaptation given the evidence that currently, in most countries, these programmes do not emphasize the cognitive and socio-emotional skills workers require to secure hard-toautomate jobs and "do not offer any benefit for avoiding automation-prone occupations and in many countries increase the likelihood of being in such occupations" (Bentaouet Kattan, 2018, p.5, p.24). Meanwhile, there is also almost certainly going to be a need to expand the offering of highly-focused bite-sized courses required to ensures workers skills remain up-to-date throughout their careers in the face of rapid technological change. What appears less clear is whether short courses, particularly online courses, are effective at building transverse skills, particularly higher cognitive and emotional skills; more research appears important to build the evidence base regarding whether such interventions are genuinely effective.

A key issue faced by many middle-income countries appears to be a lack of the systems required in order to monitor changes in skills demand and labour market shocks. Better quality labour market data can improve decisions on how to utilise the limited resources many of these countries have available for vocational training. The recommendations from The Asia Foundation's (2020, p.6-7) report on the future of work in ASEAN countries appear equally valid for middle-income countries in other regions. The authors argue for an increased focus on monitoring changes in skill demand to avoid a situation where these changes "outpace the ability of governments to track and understand these trends," thus undermining the quality of policy making. The authors advocate "building better dashboards" by "unlocking useful market data that already exists" through:

- Partnerships with the private sector;

- Reducing silos within government and improving data-sharing, and

- Deploying connected databases and artificial intelligence systems that could enable "tracking real-time trends at a massive scale."

As noted above, remote delivery of training through digital platforms has potentially significant benefits in terms of scalability, cost, quality and the geographic reach of vocational training programmes. However, this will depend on middle-income countries making appropriate investments to support effective distance learning. This should include (ILO, 2020):

- Continuing to invest in improving internet connectivity;

- Taking steps to ensure that students are able to access the required equipment to take advantage of online training opportunities;

- Invest in the development of local content and train local teachers in online training delivery; 
- Ensure students have the foundational digital skills required to take advantage of online training opportunities, and

- Invest in data protection and security systems for online learning (ILO, 2020).

Investment in digital delivery needs to be matched with other measures to improve the quality of vocational training offerings. This should include:

- Improving the capacity of teachers at vocational training institutions;

- Investing in appropriate infrastructure for vocational training institutions, so that they have the equipment they require in order to provide hands-on and relevant skills training;

- Pairing vocational training with job search and counselling services, in order to ease the transition into the workforce or new roles (Gençsü, et al., 2020), something which has been found to improve their effectiveness (Glick et al., 2015), and

- Building a stronger dialogue with employers in order to ensure that the vocational training remains connected to their needs. There is evidence that "close and active engagement with employers" improves the quality of vocational training systems (Glick et al., 2015). As the pace of labour market changes the importance of effective dialogue between skills providers and employers will increase. The Asia Foundation (2020, p.16) advocates for the importance of employers both in articulating to government the specific skills gaps that need to be plugged in the workforce and in "supporting awareness and implementation of relevant upskilling programs."

Vocational training systems should not be viewed in isolation, and are best treated as part of an integrated approach to supporting broad-based economic opportunities and social protection. Middle-income countries will need to pair efforts to develop stronger vocational training systems with:

- Improving the ability of basic education systems to equip future workers with the transversal skills that will ensure workers are able to adapt and learn in the face of labour market changes. In particular, many middle-income countries will need to improve educational standards in relation to "literacy, numeracy, digital literacy, critical thinking, creative problem solving, and emotional intelligence" (Karr et al., 2020, p.16). This point is brought home by the case of the Philippines where it is reported that "most of those who graduate from senior high school lack the skills to succeed in vocational or skills training" with many students, in particular, failing the screening to begin tech training programmes due to their "lack of critical thinking skills" (Karr et al., 2020, p.79);

- An integrated approach to reform of labour market regulations. Allais \& Marock (2020) give an example of how the effectiveness of vocational training can depend on labour market regulations; a GIZ programme in South Africa with the plumbing association identified that there were multiple plumbing courses available and strong demand for more plumbers, but that newly trained plumbers were not securing employment because "there was not a grade in the plumbing labour market for a plumbing assistant." Once this grade was created by the professional association it became much easier for those qualified to earn money and build experience towards becoming highly competent artisans; 
- Developing systems to support prioritisation of limited training resources where the need for re-training outstrips supply;

- Developing appropriate systems for "compensation, early retirement and management phase-out" where it will be impractical or inefficient to attempt to re-training all workers (e.g. workers already nearing retirement age). Germany's approach to managing the contraction of the coal and steel industry in the Ruhr Valley from the 1960s provides an example of how re-training and social protection schemes have been paired effectively in order to manage a major labour market shock (Gençsü, et al., 2020), and

- The progressive development of social safety nets, designed to maintain social stability and ensure decent living standards for all in a context in which individuals lacking - and unable to develop - higher cognitive skills may lack meaningful opportunities for dignified, reasonably paid work. Those at the forefront of the fourth industrial revolution are already thinking about this in the advanced economies, as can be seen from debate around 'universal basic income' amongst tech sector CEOs (McGaughey, 2018, p.1). With notable exceptions, such as Marais (2020) in his discussion on the potential for a Universal Basic Income in South Africa, the issue has not yet received sufficient attention for middle-income countries.

\section{How can middle-income countries improve access to vocational training post-COVID and how can vocational training contribute to reducing inequality?}

There is a general consensus in the literature on the importance of addressing equity issues in the wake of the pandemic by "paying particular attention to vulnerable groups" (OECD, 2020, p.7), including young people, migrants, women and the disabled. Achieving this will require a mixture of supply-side and demand-side orientated changes.

\section{Young people}

\section{Mounting evidence indicates that the impact of COVID-19 on young people has been} "systematic, deep and disproportionate" (ILO, 2020). In Spring 2020, 78\% of young people in lower-middle income countries and $65 \%$ of those in upper-middle income countries reported that their education had been disrupted by school closures, with even more facing class cancellations. Indeed, $20 \%$ of students in lower-middle income countries and $12 \%$ in uppermiddle income countries reported not being able to access any courses.

Young people are also at particular risk of job losses due to automation. Nedelkoska and Quintini (2018) find a U-shaped relationship between the risk of automation and employee age. However, whilst the risk of automation rises for older workers, it is "youth jobs" that are most at risk of automation and they conclude that "automation is much more likely to result in youth unemployment, than in early retirements" (Nedelkoska \& Quintini, 2018, p.8). This indicates that structured approaches to building early work experience - including internship and apprenticeship schemes - may become increasingly important as automation gathers pace. The same paper finds that employees on work-based vocational training programmes or in apprenticeships are particularly likely to be doing roles that are vulnerable to automation - this 
indicates that vocational training systems may need to be re-focused in order to ensure that participants are not acquiring skills that will rapidly become obsolete due to automation.

\section{Women}

Women in low- and middle-income countries often face particular barriers to accessing vocational training opportunities, though governments and development agencies have been attempting to address these barriers in various ways. Skills systems can improve gender equity by helping to address key skills gaps that hamper women from securing well-paid employment or achieving success as entrepreneurs. With this in mind various programmes have focused on increasing the digital skills of aspiring female entrepreneurs. The World Bank has been exploring ways of improving female completion of vocational training programmes in lowand middle-income countries. They identify three categories of adaptions to vocational training programmes that can improve outcomes for women (Hoftijzer, et al., 2020):

- Information and norm shifting. Including through communication activities designed to inform women regarding the likely financial returns to completing particular skills courses - particularly related to non-traditional occupations for females - and to increase the aspirations of women who have grown up with limited examples of females entering particular sectors, as well as the creation of peer groups to support networking by women'

- Financial support, generally through cash grants to cover transport and other training costs, and

- Operational adaptations, including (World Bank, 2020):

- Making vocational training programmes more flexible so that women are less likely to drop-out due to family and childcare commitments. In lower-middle income Kenya the World Bank encouraged such changes by financing bonuses to trainers for each woman with a child under 5 years old who completes a programme.

- Providing childcare directly or through subsidies for female participants in trainings.

- Bringing vocational training to remote communities. In both Tajikistan (which falls just short of lower middle-income country status) and lower-middle income Benin, separate World Bank projects identified that female engagement in vocational training programmes was being undermined because women felt unable to travel to major urban centres for training, reflecting social taboos and the risk of violence during travel. To address this issue the programme piloted delivery of trainings in remote areas using mobile training teams.

- Offering foundational training to women before they start vocational courses in order to address basic skills gaps that can cause them to drop out of courses. For example, in lower-middle income India the World Bank successfully raised completion of vocational training programmes in Jharkhand State by offering female participants a "life-skills" course prior to the start of their vocational training 
- Improving the learning atmosphere for women by reducing issues related to sexual harassment and abuse from training providers. For example, in India the World Bank worked with providers to ensure they implemented a code of conduct to reduce the risk of sexual harassment and abuse.

\section{The poor, informal sector workers and remote communities}

Informal sector workers often struggle to access vocational training. Workers in the informal economy - who account for $60 \%$ of employment in lower-middle income countries and $37 \%$ of employment in upper-middle income countries (Gençsü, et al., 2020) - tend to have much more limited opportunities for training over the course of their careers and courses are often not tailored to their needs. Such individuals are likely to miss out on re-training schemes tied to employment insurance systems and may lack the political weight of those working in the formal sector in traditional industries disrupted by technological change. Moreover, most informal sector employers are micro-enterprises for whom the opportunity costs of providing training to employees is simply too high (Palmer, 2017). However, it also relates to the fact that, in most middle-income countries, the needs of the informal sector are not taken into account when governments create skills development strategies and when vocational training programmes are designed, and that formal training institutions are "not generally very effective at outreaching to [employers in] the informal economy." Improving outreach and consultations with informal sector employers and workers could help to ensure that vocational training systems can adapt to meet their needs, including by providing them with opportunities to transition to the formal sector.

The Asia Foundation $(2020$, p.8) has argued for the importance of improving "accessibility and discoverability" of vocational training services. In particular, they note the importance of improved communication on vocational training opportunities to "underserved" and vulnerable groups. They suggest that the opportunity to use social media to communicate with potential beneficiaries on vocational training opportunities is not yet being exploited effectively in ASEAN countries.

The shift towards digital has huge potential benefits, but also can create equity and access issues. The expansion of internet services to remote areas and efforts to bring down the cost of accessing the internet will likely need to be prioritised in order to prevent the emergence of a digital divide in access to vocational training opportunities. There have also been calls for subsidies for internet data usage in order to encourage poorer workers to take advantage of training programmes available online (Park \& Inocencio, 2020).

\section{References}

Allais, S., \& Marock, C. (2020). Educating for work in the time of Covid-19: Moving beyond simplistic ideas of supply and demand. SARE.

https://www.researchgate.net/profile/Shafika_Isaacs/publication/343962406_Every_child_is_a_n ational_playing_asset1_A_portrait_of_a_Soweto_boy's_contradictory_worlds_of_play_and_perfo rmance_before_and_during_the_Covid-19_lockdown/links/5f4a 1b76458515a88b8426f1/Everychild-is-a-national-playing-asset1-A-portrait-of-a-Soweto-boys-contradictory-worlds-of-play-andperformance-before-and-during-the-Covid-19-lockdown.pdf\#page $=66$ 
Arntz, M., Gregory, T., \& Zierhan, U. (2016). The Risk of Automation for Jobs in OECD Countries. https://www.oecd-ilibrary.org/social-issues-migration-health/the-risk-of-automation-forjobs-in-oecd-countries_5jlz9h56dvq7-en

Attanasio, O., Guarín, A., Medina, C., \& Meghir, C. (2015). Long term impacts of vouchers for vocational training: Experimental evidence for Colombia. National Bureau of Economic Research. https://www.nber.org/system/files/working_papers/w21390/w21390.pdf

Avis, J., Atkins, L., Esmond, B., \& McGrath, S. (2021). Re-conceptualising VET: responses to covid-19. Journal of Vocational Education \& Training, 1-23.

https://www.tandfonline.com/doi/abs/10.1080/13636820.2020.1861068?casa_token=YHY5ou4_ ODoAAAAA:VFvBCfVG2QY8i3So911-ib2SX-c9Ng4nZnujHBh2ycnXjhAWim_u-

1GhlHgZ1i5qEiQvJarJZ_0

Banga, K and te Velde, D.W. Skill needs for the future. Pathways for Prosperity Commission Background Paper Series; no. 10. Oxford, United Kingdom.

https://pathwayscommission.bsg.ox.ac.uk/skill-needs-for-the-future

Barnow, B. S. (2009). Vouchers in US vocational training programs: An overview of what we have learned. Zeitschrift Für Arbeitsmarktforschung, 42(1), 71-84.

https://link.springer.com/content/pdf/10.1007/s12651-009-0007-9.pdf

Beegle, K., \& Rubiano-Matulevich, E. (2020). Adapting Skills Training to Address Constraints to Women's Participation. https://openknowledge.worldbank.org/handle/10986/33694

Bentaouet Kattan, R., Macdonald, K., \& Patrinos, H. A. (2018). Automation and labor market outcomes: The pivotal role of high-quality education. The World Bank.

https://openknowledge.worldbank.org/bitstream/handle/10986/29903/WPS8474. pdf? sequence=1

BILSLAND, C., Nagy, H., \& Smith, P. (2020). Virtual internships and work-integrated learning in hospitality and tourism in a post-COVID-19 world. International Journal of Work-Integrated Learning, 21(4), 425-437.

https://www.researchgate.net/profile/Christine_Bilsland/publication/344575852_Virtual_internship s_and_work-integrated_learning_in_hospitality_and_tourism_in_a_post-COVID-

19_world/links/5f80fbdfa6fdccfd7b554acd/Virtual-internships-and-work-integrated-learning-inhospitality-and-tourism-in-a-post-COVID-19-world.pdf

Bughin, J., Hazan, E., Lund, S., Dahlström, P., Wiesinger, A., \& Subramaniam, A. (2018). Skill shift: Automation and the future of the workforce. McKinsey Global Institute, 1, 3-84. https://www.voced.edu.au/content/ngv:79805

Buheji, M., Buheji, A., \& others. (2020). Planning competency in the new Normal-employability competency in post-COVID-19 pandemic. International Journal of Human Resource Studies, 10(2), 237-251.

https://pdfs.semanticscholar.org/572f/3d8e96a380648cbd464e21e7500a0d808681.pdf 
Chetty, K., Aneja, U., Mishra, V., Gcora, N., \& Josie, J. (2017). Bridging the digital divide: Skills for the new age. http://repository.hsrc.ac.za/handle/20.500.11910/10839

Chinen, M., De Hoop, T., Alcázar, L., Balarin, M., \& Sennett, J. (2017). Vocational and business training to improve women's labour market outcomes in low-and middle-income countries: A systematic review. Campbell Systematic Reviews, 13(1), 1-195.

https://onlinelibrary.wiley.com/doi/pdf/10.4073/csr.2017.16

Co-operation, O. for E., \& Development (OECD). (2020). VET in a time of crisis: Building foundations for resilient vocational education and training systems.

https://www.voced.edu.au/content/ngv:86460

Cuaresma, J. C., Lutz, W., \& Sanderson, W. (2014). Is the demographic dividend an education dividend? Demography, 51(1), 299-315. https://link.springer.com/article/10.1007/s13524-0130245-x\%23author-details-1

Dao, M. C., Das, M. M., Koczan, Z., \& Lian, W. (2017). Why is labor receiving a smaller share of global income? Theory and empirical evidence. International Monetary Fund. https://www.imf.org/ /media/Files/Publications/WP/2017/wp17169.ashx

Doner, R., \& Schneider, B. R. (2020). Technical education in the middle income trap: Building coalitions for skill formation. The Journal of Development Studies, 56(4), 680-697. https://www.tandfonline.com/doi/pdf/10.1080/00220388.2019.1595597?casa_token=kcGTnL2eX MwAAAAA:avP7yFZCK9_12SMBFSkM2DbdMZ76h1b0IHzpR101kbLGhrgcyaHDr9lp7kVUIOsog IFkQzYGWG0

Draissi, Z., \& ZhanYong, Q. (2020). COVID-19 Outbreak Response Plan: Implementing Distance Education in Moroccan Universities. Available at SSRN 3586783.

https://papers.ssrn.com/sol3/papers.cfm?abstract_id=3586783

Drummond, M. P., Thakoor, V., \& Yu, S. (2014). Africa rising: Harnessing the demographic dividend. International Monetary Fund. http://faculty.wwu.edu/patrick/envs342geo312/Readings/4-Bloom-Demographic\%20Dividend/Africa-wp14143.pdf

Eichengreen, B., Park, D., \& Shin, K. (2013). Growth slowdowns redux: New evidence on the middle-income trap. National Bureau of Economic Research.

https://www.nber.org/system/files/working_papers/w18673/w18673.pdf

Ejiogu, A., Okechukwu, O., \& Ejiogu, C. (2020). Nigerian budgetary response to the COVID-19 pandemic and its shrinking fiscal space: Financial sustainability, employment, social inequality and business implications. Journal of Public Budgeting, Accounting \& Financial Management. https://leicester.figshare.com/articles/journal_contribution/Nigerian_budgetary_response_to_the_ COVID-

19_pandemic_and_its_shrinking_fiscal_space_financial_sustainability_employment_social_ineq uality_and_business_implications/12967829/files/24704012.pdf

Enfield, S., (2021). Covid-19 impact on employment and skills for the labour market. 
K4D Helpdesk Report. Brighton, UK: Institute of Development Studies. DOI: 10.19088/K4D.2021.081.

https://opendocs.ids.ac.uk/opendocs/bitstream/handle/20.500.12413/16609/956_Covid19_and_e mployment.pdf?sequence=1\&isAllowed $=y$

Engineering Council. (2011). Gateways Development Fund Project: Flexible Pathways to becoming a Professional Engineer - review of activity 2006 -2011. Engineering Council. https://www.engc.org.uk/media/3095/110318-ds-5-year-report-paper-published.pdf

Fleisher, B. M., McGuire, W., Su, Y., \& Zhao, M. Q. (2018). Innovation, Wages, and Polarization in China. https://www.econstor.eu/bitstream/10419/180587/1/dp11569.pdf

Frey, C. B., \& Osborne, M. (2013). The future of employment. http://sep4u.gr/wpcontent/uploads/The_Future_of_Employment_ox_2013.pdf

Gençsü, I., Grayson, A., Mason, N., \& Foresti, M. (n.d.). Migration and skills for the low-carbon transition. https://apo.org.au/node/307391

Glick, P. J., Huang, C., \& Mejia, N. (2015). The private sector and youth skills and employment programs in low and middle-income countries.

https://openknowledge.worldbank.org/bitstream/handle/10986/23260/The0private0se0dle0incom e0countries.pdf?sequence $=1$

Gonzalez, S. P., Gardiner, D., \& Bausch, J. (2020). Youth and COVID-19: Impacts on jobs, education, rights and mental well-being: Survey report 2020. ILO, Geneva, 5.

https://www.voced.edu.au/content/ngv:87705

Goyal, A. (2020). Post COVID-19: Recovering and sustaining India's growth. Indian Economic Review, 55(1), 161-181. https://link.springer.com/article/10.1007/s41775-020-00089-z

Ha, J., \& Lee, S.-H. (2016). Demographic dividend and Asia's economic convergence towards the US. The Journal of the Economics of Ageing, 8, 28-41.

https://www.sciencedirect.com/science/article/pii/S2212828X15300232?casa_token=c98OAYmw tkQAAAAA:R-pl-TLGjw3xMlqEJ9qJ_URDnAWIAr34o-nz87dasHa7hn3PN-iHOfgp5kBH-

iHZGuaJ3D1q

Herbert, G. (2020). Factors effecting inclusive economic resilience in middle-income countries. K4D Helpdesk Report. Brighton, UK: Institute of Development Studies.

https://opendocs.ids.ac.uk/opendocs/bitstream/handle/20.500.12413/15726/877_economic_resili ence_in_middle-income_countries.pdf?sequence=1

Herbert, G., \& Loudon, L. (2020). The Size and Growth Potential of the Digital Economy in ODAeligible Countries. https://opendocs.ids.ac.uk/opendocs/handle/20.500.12413/15963

Hofheinz, P. (2018). Value creation in the data-driven economy. Praise for Work in the Digital Age, 89. http://bruegel.org/wp-content/uploads/2018/07/Work-in-the-Digital-Age.pdf\#page=112 
Hoftijzer, M., Levin, V., Santos, I., \& Weber, M. (2020). TVET Systems' response to COVID-19: Challenges and Opportunities. World Bank.

https://openknowledge.worldbank.org/bitstream/handle/10986/33759/TVET-Systems-responseto-COVID-19-Challenges-and-Opportunities.pdf?sequence $=1$

ILO. (2019). SKILLS FOR A GREENER FUTURE: Challenges and enabling factors to achieve a just transition. https://www.ilo.org/wcmsp5/groups/public/--ed_emp/documents/publication/wcms_731957.pdf

ILO. (2020). Preventing exclusion from the labour market: Tackling the COVID-19 youth employment crisis. https://www.ilo.org/wcmsp5/groups/public/--ed_emp/documents/publication/wcms_746031.pdf

Jain, S., \& Sasiprabhu, S. (n.d.). Tech to the rescue: How to make Africa's digital transformation work for resilience. THE DAY AFTER TOMORROW. https://www.orfonline.org/wpcontent/uploads/2020/07/ORF_Report_Africa-DayAfterTomorrow1.pdf\#page=138

Karr, J., Lokshin, B., Loh, K., \& others. (2020). The Future of Work Across ASEAN: Policy Prerequisites for the Fourth Industrial Revolution. https://thinkasia.org/bitstream/handle/11540/11663/The-Future-of-Work-AcrossASEAN_full.pdf?sequence $=1$

Lobo, Í. A. (2016). Technical and vocational education and training institutions and programmes in Mexico. Protection and Training Institutions for Improving Workforce Integration in Latin America and Asia, 315-334. https://www.un-ilibrary.org/content/books/9789210575478s004c004

Majumdar, S., Araiztegui, I., \& Tknika, B. V. (2020). Technical Vocational Education \& Trainingreflections on the issues facing TVET and its potential in the time of COVID-19.

http://www.leidoacademy.nl/doorzeven/wp-content/uploads/2020/05/FINAL-COVID19UNESCO.pdf

Marais, H. (2020). The crisis of waged work and the option of a universal basic income grant for South Africa. Globalizations, 17(2), 352-379.

https://www.tandfonline.com/doi/pdf/10.1080/14747731.2019.1652469?casa_token=FhqPVSqKcAAAAAA:TUfKIO3bnUG72LWp0Z5a19sy-T-L7MSr23KC6AGZvJRIrMI-_UEh_csivnGGQvY7hZOn9bU974

McGaughey, E. (2018). Will robots automate your job away? Full employment, basic income, and economic democracy. Centre for Business Research, University of Cambridge, Working Paper, 496. https://www.cbr.cam.ac.uk/fileadmin/user_upload/centre-for-business-

research/downloads/working-papers/wp496.pdf

Nedelkoska, L., \& Quintini, G. (2018). Automation, skills use and training. https://www.oecdilibrary.org/content/paper/2e2f4eea-en 
Palmer, R. (2017). Jobs and skills mismatch in the informal economy. Ginebra: OIT. Recuperado de https://www. ilo. org/wcmsp5/groups/public .... http://www.oit.org/wcmsp5/groups/public/--ed_emp/---ifp_skills/documents/publication/wcms_629018.pdf

Park, C.-Y., \& Inocencio, A. M. (2020). COVID-19, Technology, and Polarizing Jobs. Asian Development Bank. https://www.adb.org/sites/default/files/publication/623036/covid-19technology-polarizing-jobs.pdf

Parker, R., Morris, K., \& Hofmeyr, J. (2020). Education, inequality and innovation in the time of COVID-19. Johannesburg: Jet Education. https://www.jet.org.za/resources/theme-9-final-july2020-parker-et-

al.pdf/@@download/file/Theme\%209\%20Final\%20report\%20Parker\%20et\%20al.pdf

Pearson, M. (2020). A meta-analysis of COVID-19: Challenging Australias' Vocational Education sector. Journal of Vocational Education Studies, 3(2), 53-60.

https://www.researchgate.net/profile/Matthew_Pearson11/publication/348301389_A_metaanalysis_of_COVID-

19_Challenging_Australias'_Vocational_Education_sector/links/5ff77c5b92851c13fef7cf65/Ameta-analysis-of-COVID-19-Challenging-Australias-Vocational-Education-sector.pdf

Pellini, A., Weyrauch, V., Malho, M., \& Carden, F. (2019). State capability, policymaking and the Fourth Industrial Revolution: Do knowledge systems matter. Ginebra: Capability, Demos Helsinki, HELVETAS Swiss Intercooperation .... http://politicsandideas.org/wpcontent/uploads/2019/02/Discussion_Paper_4IR_KS_20190118_Final.pdf

Pennington, A., Stanford, J., \& others. (2020). Rebuilding after COVID-19 will need a sustained national reconstruction plan. Journal of Australian Political Economy, The, 85, 164. https://www.ppesydney.net/content/uploads/2020/06/24_Pennington-and-Stanford.pdf

Poudel, T. (2020). Policy Documents of Nepali Technical and Vocational Education and Training: A Critical Discourse Analysis. Journal of Education and Research, 10(1), 1-15. https://www.nepjol.info/index.php/JER/article/download/31872/25190

Sancak, M. (2020). Partisan politics of skills in middle-income countries: Insiders, outsiders and the vocational education system of Turkey. Competition \& Change, 24(3-4), 291-314. https://journals.sagepub.com/doi/pdf/10.1177/1024529419888430?casa_token=Za4XjQWFMkAAAAA:8A1MVSr5rmNiF4UluGGGm3kAAEZ0KrFZMN5Zp5JDCwuWkmNnAg70u5AH6MPBdbltG1ybETTs0

Sa-Nguanmanasak, T., \& Khampirat, B. (2019). Comparing employability skills of technical and vocational education students of Thailand and Malaysia: A case study of international industrial work-integrated learning. Journal of Technical Education and Training, 11(3).

https://publisher.uthm.edu.my/ojs/index.php/JTET/article/download/4280/3143 
Schwab, K. (2017). The fourth industrial revolution. Currency.

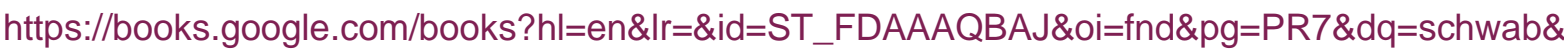
ots=DUgy5PswWM\&sig=W8z9hNY2tUr_Ix4rGA8c8Fau9D0

Shiohira, K., \& Keevy, J. (2020). Virtual Conference on Artificial Intelligence in Education and Training: Virtual Conference Report. UNESCO-UNEVOC TVeT Forum, 11 to 15 November 2019. UNESCO-UNEVOC International Centre for Technical and Vocational Education and Training. https://eric.ed.gov/?id=ED604935

Siu, H., \& Jaimovich, N. (2015). Jobless recoveries. Retrieved May, 6, 2015. https://henrysiu.com/pubs/NEXT_-_Jobless_Recoveries.pdf

Tripney, J., Hombrados, J., Newman, M., Hovish, K., Brown, C., Steinka-Fry, K., \& Wilkey, E. (2013). Technical and vocational education and training (TVET) interventions to improve the employability and employment of young people in low-and middle-income countries: A systematic review. Campbell Systematic Reviews, 9(1), 1-171.

https://onlinelibrary.wiley.com/doi/pdf/10.4073/csr.2013.9

Woo, J. (2020). Policy capacity and Singapore's response to the COVID-19 pandemic. Policy and Society, 39(3), 345-362.

https://www.tandfonline.com/doi/pdf/10.1080/14494035.2020.1783789

World Economic Forum. (2017). Realizing human potential in the Fourth Industrial Revolution: An agenda for leaders to shape the future of education, gender and work. World Economic Forum. https://www.voced.edu.au/content/ngv:75141 


\section{Suggested citation}

Herbert, G., (2021). How can middle-income countries improve their skills systems post-COVID19? K4D Helpdesk Report 957. Brighton, UK: Institute of Development Studies. DOI:

10.19088/K4D.2021.082

\section{About this report}

This report is based on six days of desk-based research. The K4D research helpdesk provides rapid syntheses of a selection of recent relevant literature and international expert thinking in response to specific questions relating to international development. For any enquiries, contact helpdesk@k4d.info.

K4D services are provided by a consortium of leading organisations working in international development, led by the Institute of Development Studies (IDS), with Education Development Trust, Itad, University of Leeds Nuffield Centre for International Health and Development, Liverpool School of Tropical Medicine (LSTM), University of Birmingham International Development Department (IDD) and the University of Manchester Humanitarian and Conflict Response Institute (HCRI).

This report was prepared for the UK Government's Foreign, Commonwealth and Development Office (FCDO) and its partners in support of pro-poor programmes. Except where otherwise stated, it is licensed for non-commercial purposes under the terms of the Open Government Licence v3.0. K4D cannot be held responsible for errors, omissions or any consequences arising from the use of information contained in this report. Any views and opinions expressed do not necessarily reflect those of FCDO, K4D or any other contributing organisation.

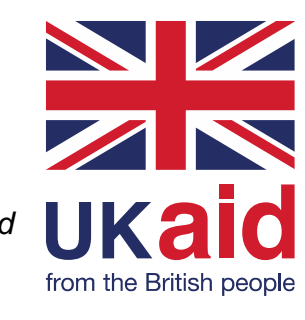

(c) Crown copyright 2021. 